\title{
Analyzing the Revision Logs of a Japanese Newspaper for Article Quality Assessment
}

\author{
Hideaki Tamori $^{1} \quad$ Yuta Hitomi $^{1} \quad$ Naoaki Okazaki $^{2} \quad$ Kentaro Inui $^{3}$ \\ ${ }^{1}$ Media Lab, The Asahi Shimbun Company \\ 2 Tokyo Institute of Technology \\ ${ }^{3}$ Tohoku University \\ \{tamori-h, hitomi-yl\}@asahi.com, okazaki@chokkan.org \\ inuidecei.tohoku.ac.jp
}

\begin{abstract}
We address the issue of the quality of journalism and analyze daily article revision logs from a Japanese newspaper company. The revision logs contain data that can help reveal the requirements of quality journalism such as the types and number of edit operations and aspects commonly focused in revision. This study also discusses potential applications such as quality assessment and automatic article revision as our future research directions.
\end{abstract}

\section{Introduction}

Quality journalism deserves serious consideration, particularly given the disruptions of existing publishing companies and the emergence of new publishing companies, citizen journalism, and automated journalism. Although no consensus exists for the definition of quality journalism, Meyer (2009) describes several aspects that constitute quality journalism; for example, credibility, influence, accuracy, and readability. To the best of our knowledge, this is the first attempt to analyze the large-scale revision logs of professionals in the field of journalism. In this study, we explore aspects of quality journalism through analyses of the newspaper article revision logs. More specifically, we analyze the revision processes as editors refine the drafts written by reporters so that they are of publication quality.

While our attempt is still in the early stages, this paper reports the statistics of the actual revisions made by professionals and shows the usefulness of the revision logs. We also discuss the future directions of this research, for example, the potential to present feedback to reporters, extract guidelines for 'good' articles, and develop systems for automatic revision and sentence merging and spitting.

\section{Analysis of revision logs}

This section describes the daily activities of a newspaper company needed to publish articles and the analysis of the revision logs.

\subsection{Flow of editing and publishing articles}

A reporter drafts an article and sends it to an editor, who has over ten years' experience as a journalist. The editor proofreads the article and forwards it to a reviewers section. The reviewers in this section fact-check the article. Finally, designers adjust the article so that they fit in the newspaper and website. In this way, a newspaper article is revised many times from the original submission.

Figure 1 compares the text from an article written by a reporter and the same text after it has been revised by an editor. The editor revises the text using insertion, deletion, and replacement. This example also shows the operations of sentence reordering and splitting.

\subsection{Aligning original sentences with revised sentences}

Revision logs present two versions of an article: the one written by a reporter (the original version) and the final version revised by an editor (the revised version). However, these logs do not provide details about the editing process used to transform the original version into the final version (e.g., individual operations of word insertion/deletion, sentence reordering). Hence, we estimate sentence alignments between the original and revised versions using the maximum alignment method (Kajiwara and Komachi, 2016).

The accuracy, precision, recall, and F1 score were $0.995,0.996,0.951$, and 0.957 , respectively, on a dataset consisting of 50 articles in which the correct alignments were assigned by a human. ${ }^{1}$

\footnotetext{
${ }^{1}$ We chose 0.06 for word similarity threshold and 0.70 for
} 
Reporter

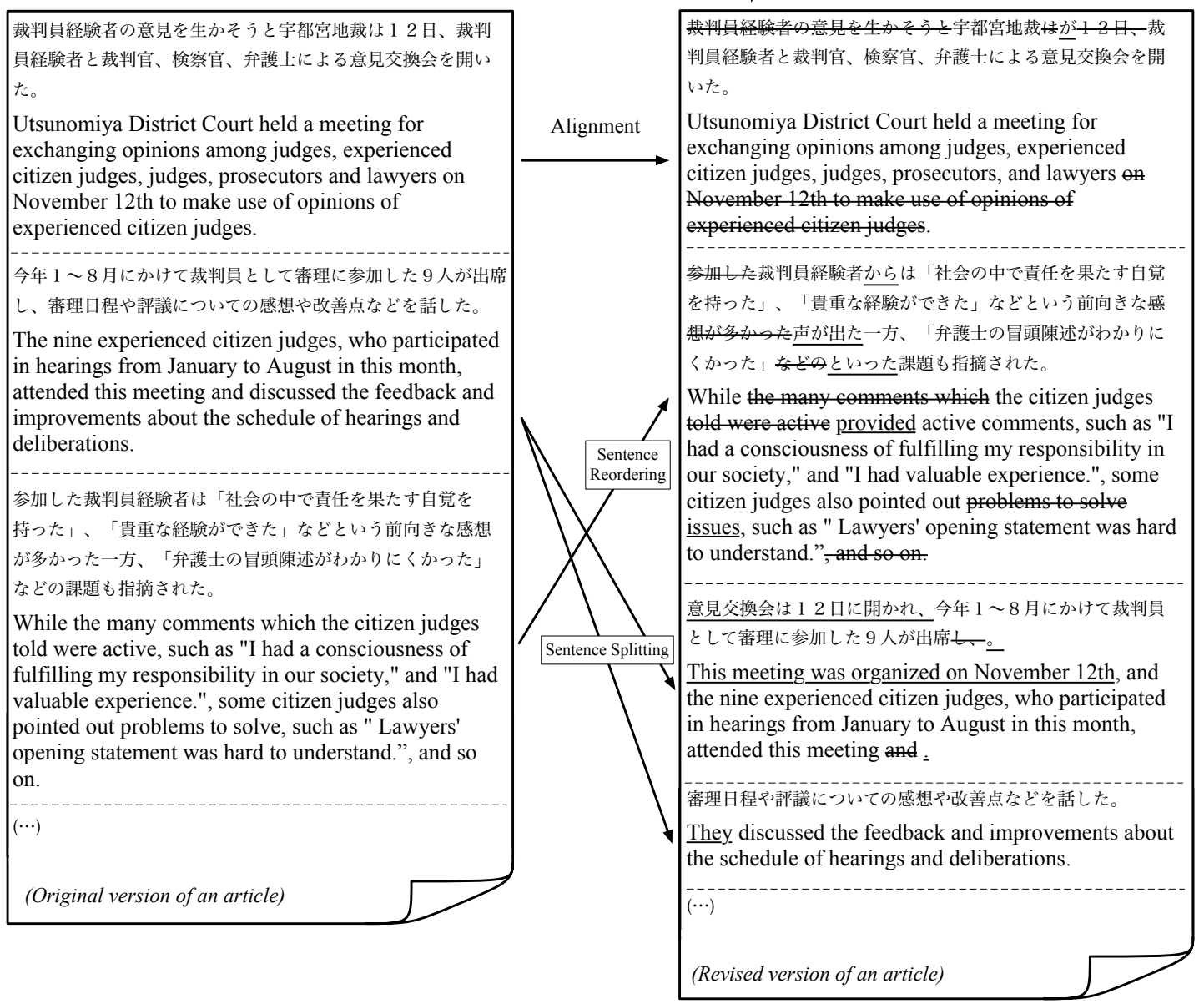

Figure 1: Comparison of the original and revised versions of some text. In the revised version, the strikethrough and underlined parts indicate deletions and insertions, respectively.

The precision, recall, and F1 score calculated from only the sentence pairs that are changed during revision were $0.926,0.895$, and 0.910 , respectively. There may be some room for improving the performance of the alignments but it is sufficient for this analysis.

\subsection{Data analysis of the revision logs}

To analyze the details of the revision processes, we inspected articles published from October 1, 2015 to September 30, 2016. We applied MeCab (Kudo et al., 2004), a Japanese morphological analyzer, with the enhanced dictionary NE$\operatorname{olog} d^{2}$, to split the sentences into words (morphemes) and recognize their parts-of-speech.

sentence similarity threshold, optimizing the F1 score on a development set consisting of 150 articles. We used word embeddings that are pre-trained by the original articles and revised articles to compute sentence similarity.

${ }^{2}$ https://github.com/neologd/mecab-ipadic-neologd
The dataset analyzed in this study contains 120,331 articles with $1,903,645$ original sentences and 1,884,987 revised sentences. The dataset consists of a Japanese newspaper's articles ${ }^{3}$, which have a mixed domain (genre) of the news, and most of the articles have the same writing style. We obtained 2,197,739 sentence pairs using the alignment method described in Section 2.2. The number of aligned pairs is larger than that of the sentences because an original sentence can be aligned to multiple sentences in the revised version. About half of the sentence pairs $(1,108,750)$ were unchanged during the revision process, and the remaining pairs $(1,088,989)$ were changed. In this section, we report the statistics of the edit operations in the changed pairs. We found that newspaper companies produce a huge number of sentences, about half of which are revised, for analy-

\footnotetext{
${ }^{3}$ The Asahi Shimbun Company provided this dataset.
} 


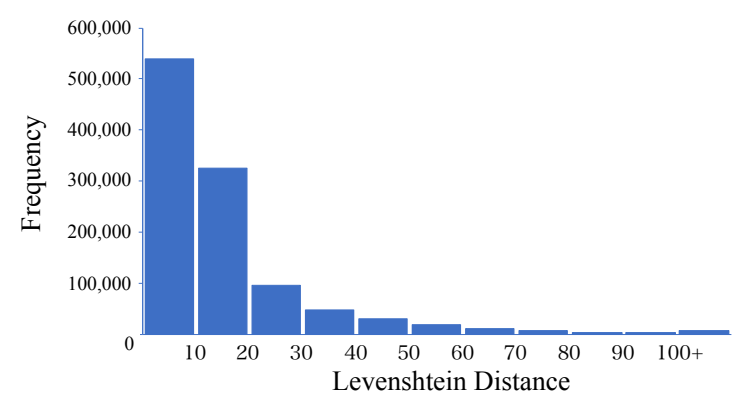

Figure 2: Distribution of the Levenshtein distance of changed sentence pairs.

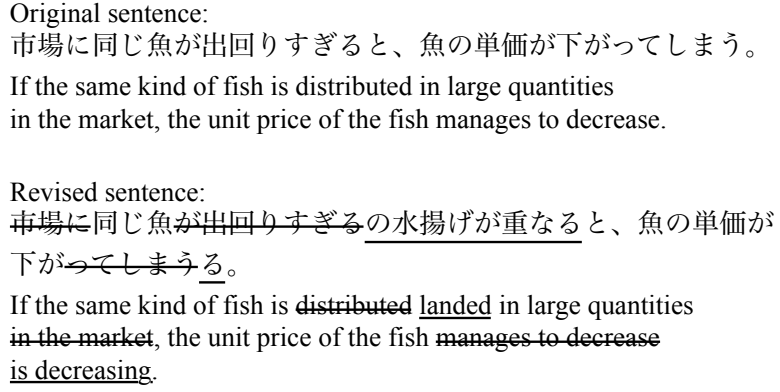

Figure 3: An example of the original and revised sentence pair whose Levenshtein distance is 15 .

sis just within a year.

Figure 2 presents the distribution of the Levenshtein distance between the original and revised sentences. The mean of the Levenshtein distances of the revised pairs (15.04) indicates that the dataset includes many examples in which drafts are deeply edited by the editors. Figure 3 is an example of the sentence pair which has the mean of the Levenshtein distance of the dataset (15).

Table 1 lists the number of insertions, deletions, and replacements, according to the number of words involved in the edit operations. We found that $56.20 \%$ of the total edit operations were replacements for one or two words, and this fact indicates that editors revised these articles with impressive attention to detail.

Table 2 shows the number of edit operations separated by different part-of-speech. The most frequent target for revisions is nouns, followed by particles (postpositions). This result indicates that revisions in terms of both content and readability are important for improving the quality of articles.

\begin{tabular}{|l|l|l|l|}
\hline \# of words & Insertion & Deletion & Replacement \\
\hline 1 & 139,790 & 160,975 & $1,424,118$ \\
2 & 118,261 & 151,641 & 303,293 \\
3 & 57,397 & 53,789 & 115,525 \\
4 & 35,272 & 31,719 & 75,909 \\
5 & 21,339 & 20,435 & 33,805 \\
6 & 13,295 & 14,756 & 21,419 \\
7 & 14,599 & 13,030 & 24,400 \\
8 & 8,631 & 9,301 & 10,707 \\
9 & 10,196 & 10,760 & 8,475 \\
Over 10 & 48,754 & 60,523 & 61,387 \\
\hline Total & 467,534 & 526,929 & $2,079,038$ \\
\hline
\end{tabular}

Table 1: Number of edit operations with respect to the number of words involved.

\begin{tabular}{|l|l|}
\hline Tag & Count \\
\hline Noun & $1,255,113$ \\
Noun + Noun & 174,306 \\
Particle & 157,840 \\
Symbol & 128,584 \\
Noun + Particle & 106,548 \\
Verb & 85,709 \\
Symbol + Noun & 47,635 \\
Particle + Noun & 42,714 \\
Particle + Verb & 41,342 \\
Prefix & 41,194 \\
Noun + Symbol & 37,580 \\
Verb + Auxiliary & 20,836 \\
Auxiliary & 18,145 \\
Noun + Verb & 14,153 \\
Adverb & 9,009 \\
Others & 101,714 \\
\hline
\end{tabular}

Table 2: Distribution of parts-of-speech as targets for the edit operations involving one or two words.

\section{Future directions for quality assessment and automatic article revision}

There are several possible future directions for the utilization of the revision logs.

\subsection{Feedbacks to reporters}

We can use the revision logs for improving the writing skills of reporters. An interesting finding in the revision logs is that the articles of young reporters (1-3 years' experience) tend to be revised more than those of experienced reporters (31-33 years' experience): the mean Levenshtein distances of these young and experienced reporters are 15.82 and 12.95, respectively. As exemplified by this finding, the revision logs can indicate the main types of revisions that a particular group of reporters or an individual reporter receives. We will explore the potential of the revision logs for assessing the writing quality of a reporter and presenting them with feedback. 


\subsection{Establishing guidelines for writing articles}

Most textbooks on Japanese writing (including the internal handbook for reporters produced by the newspaper company) recommend that a Japanese sentence should be 40 to 50 characters long (Ishioka and Kameda, 2006). We could confirm that the newspaper articles satisfy this criterion: the revised sentences are 41.10 characters long on average. In this way, we can analyze the revision logs to extract various criteria for establishing the guidelines for 'good' articles.

\subsection{Automatic article revision within sentences}

Another future direction is to build a corpus for improving the quality of articles. The revision logs collected for a year (excluding duplicates) provide 517,545 instances of replace operations, 79,639 instances of insertions, and 54,111 instances of deletions that involve one or two words. Table 3 shows some instances of the replace operations. It may not be straightforward to use the revision logs for error correction because some edit operations add new information and remove useless information. Nevertheless, the logs record the daily activities of how drafts are improved by the editors. In future, we plan to build an editing system that detects errors and suggests wording while the reporters write drafts. We can use natural language processing techniques for these tasks because local error correction has been previously researched (Cucerzan and Brill, 2004).

\subsection{Automatic sentence merging and splitting}

The alignment method found 69,891 instances of sentence splitting (wherein an original sentence is split into multiple sentences) and 68,550 instances of sentence merging (wherein multiple original sentences are merged into one sentence). Table 4 shows examples of sentence splitting and merging. We observe some sentences are also compressed during sentence merging and splitting. We can use these instances as a training data for building a model for sentence splitting and merging (with compression), and this may be an interesting task in the field of natural language processing.

\section{Conclusion}

In this paper, we explored the potential of the revision logs of a newspaper company for assessing

\begin{tabular}{|l|l|}
\hline Original & Revised \\
\hline $\begin{array}{l}\text { 同政府関係者 } \\
\text { this Government offi- } \\
\text { cials }\end{array}$ & $\begin{array}{l}\text { 韓国政府関係者 } \\
\text { Korean Government of- } \\
\text { ficials: specification }\end{array}$ \\
\hline $\begin{array}{l}\text { 放射線污染 } \\
\text { contamination by radial } \\
\text { ray }\end{array}$ & $\begin{array}{l}\text { 放射能污染 } \\
\text { radiologically contami- } \\
\text { nation }\end{array}$ \\
\hline $\begin{array}{l}\text { 破顔し } \\
\text { broke into a smile }\end{array}$ & $\begin{array}{l}\text { 笑顔で話し } \\
\text { spoke with a smile: } \\
\text { simplification }\end{array}$ \\
\hline バラテイ & $\begin{array}{l}\text { バラエテイー } \\
\text { Varety }\end{array}$ \\
\hline $\begin{array}{l}\text { タンパク質 } \\
\text { Protain: typo } \\
\text { Katakana and Kanji in }\end{array}$ & $\begin{array}{l}\text { たんぱく質 } \\
\text { Protain: written in Hi- } \\
\text { ragana and Kanji }\end{array}$ \\
\hline $\begin{array}{l}\text { 買えた } \\
\text { could buy }\end{array}$ & $\begin{array}{l}\text { 買える } \\
\text { can buy }\end{array}$ \\
\hline
\end{tabular}

Table 3: Examples of commonly replaced words/phrases.

\begin{tabular}{|c|c|}
\hline \multicolumn{2}{|c|}{ Splitting } \\
\hline (S1) & 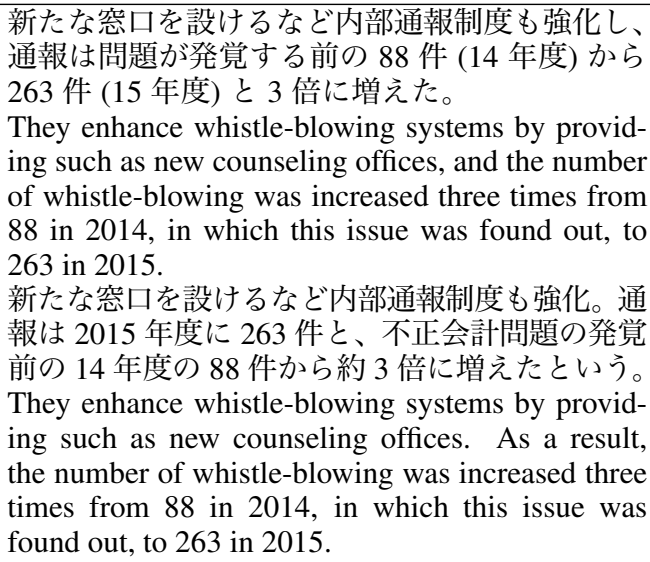 \\
\hline$\frac{\text { Merg }}{\text { (M1) }}$ & $\begin{array}{l}\text { ling } \\
\text { 同署によると、事務所南側 } 1 \text { 階の空が割られ、室 } \\
\text { 内にある防犯カメラのモニ台台がすへて壊 } \\
\text { されていた。食器棚も倒され、食器が散乱してい } \\
\text { たという。 } \\
\text { Police said that the window on the first floor of the } \\
\text { office south is broken, and all four displays for the } \\
\text { security camera was destroyed. Police also said that } \\
\text { the cupboard was knocked down, and the dished are } \\
\text { scattered in the room. } \\
\text { 署によると、室内の防犯カメラのモニター全 } 4 \text { 台 } \\
\text { が壊され、食棚が倒れて食器が散乱していた。 } \\
\text { Police said the all four displays for the security cam- } \\
\text { era was destroyed, the cupboard was knocked down, } \\
\text { and the dished are scattered in the room. }\end{array}$ \\
\hline
\end{tabular}

Table 4: Examples of sentence splitting and merging. Sentences S1 and M1 are the original sentences, and $\mathrm{S} 2$ and $\mathrm{M} 2$ are the revised sentences. In the merging example, we can also observe the sentence compressing; the part "the window on the first floor of the office south is broken" was eliminated in M2.

the quality of articles. In addition to presenting the revision logs statistics, we discussed the future 
directions of this work, which include feedback to reporters, guidelines for 'good' articles, automatic article revision, and automatic sentence merging and splitting.

\section{References}

Silviu Cucerzan and Eric Brill. 2004. Spelling correction as an iterative process that exploits the collective knowledge of web users. In Proc of EMNLP. pages 293-300.

Tsunenori Ishioka and Masayuki Kameda. 2006. Automated Japanese essay scoring system based on articles written by experts. In Proc of ACL. pages 233 240.

Tomoyuki Kajiwara and Mamoru Komachi. 2016. Building a monolingual parallel corpus for text simplification using sentence similarity based on alignment between word embeddings. In Proc of COLING. pages 1147-1158.

Taku Kudo, Kaoru Yamamoto, and Yuji Matsumoto. 2004. Applying conditional random fields to Japanese morphological analysis. In Proc of EMNLP. pages 230-237.

Philip Meyer. 2009. The vanishing newspaper : saving journalism in the information age. University of Missouri Press, Columbia. 